\title{
Argentina, tierra de machos y señoras gordas. Género, masculinidad y política en Tacuara
}

\author{
Argentina, land of macho man and fat ladies. \\ Gender, manliness and politics in Tacuara
}

\author{
Esteban Campos \\ Instituto de Historia Argentina y Americana Dr. Emilio Ravignani; \\ Consejo Nacional de Investigaciones Científicas y Técnicas (Argentina) \\ estebancampos1977@gmail.com
}

\begin{abstract}
Resumen
El propósito de este artículo es analizar las representaciones sexo-genéricas en la prensa política del Movimiento Nacionalista Tacuara (MNT), perteneciente al campo de la derecha nacionalista, y el Movimiento Nacionalista Revolucionario Tacuara (MNRT), una escisión del primero que se desplazó a posiciones lindantes con la izquierda peronista. A partir de la observación de periódicos como Tacuara. Vocero de la juventud nacionalista y Ofensiva del MNT, Barricada y Tacuara del manchón del MNRT en los años que van entre 1958 y 1964, planteo que la construcción de estereotipos de género en la prensa de la Tacuara nacionalista y la Tacuara revolucionaria es indisociable de su discurso político. Estas referencias se repiten de manera sistemática hasta convertirse en un tópico discursivo del MNT, mientras que en los medios gráficos del MNRT ocupan un lugar marginal. En la insistencia de vincular la política con el género subyacía una práctica discursiva que exaltaba la virilidad como un atributo masculino propiamente nacionalista. Del otro lado, la oposición y sus símbolos eran ridiculizados en términos misóginos y homofóbicos.
\end{abstract}

\section{Palabras clave}

Estereotipos de género; Masculinidades; Misoginia; Homofobia; Virilidad; Prensa tacuarista

\begin{abstract}
The purpose of this article is to analyze the sex-gender representations in the political press of the Nationalist Movement Tacuara (MNT), belonging to the field of the nationalist right, and the Nationalist Revolutionary Movement Tacuara (MNRT), a split of the first that moved to positions bordering the Peronist left. From the observation of magazines like Tacuara. Spokesman of the nationalist youth and Offensive of the MNT, Barricade and Tacuara del manchón of the MNRT in the years between 1958 and 1964, I propose that the construction of gender stereotypes in the press of the nacionalist Tacuara and the revolutionary Tacuara is inseparable from their political discourse. These references are repeated systematically until they become a discursive topic of the MNT, while in the graphic media of the MNRT they occupy a marginal place. In the insistence of linking politics with gender, there was a discursive practice that exalted virility as a properly nationalist attribute of the males. On
\end{abstract}

Esta obra está sujeta a la Licencia Reconocimiento-NoComercial-CompartirIgual 4.0 Internacional de Creative Commons. http://creativecommons.org/licenses/by-nc-sa/4.0/ 


\title{
Argentina, tierra de machos y señoras gordas. Género, masculinidad y política en Tacuara
}

the other side, the opposition and its symbols were ridiculed in misogynistic and homophobic terms.

Keywords

Gender stereotypes; Masculinities; Misogyny; Homophobia; Virility; Tacuarist press

\begin{abstract}
"Hubo una revolución feminista. Se articularon discursos, a pesar del decoro y frente a la hostilidad. Y eso sigue en marcha. Pero, de momento, nada con respecto a la masculinidad (...) El sexo que se dice fuerte es precisamente el que hay que proteger sin cesar, el que hay que confortar, curar y cuidar. Al que hay que proteger contra la verdad. Las mujeres son tan cabronas como ellos y los hombres tan putos y tan madres como ellas, todos estamos en medio de la misma confusión. Hay hombres que están hechos para ocuparse del jardin, de la decoración interior y para llevar a los niños al parque; y mujeres con un cuerpo capaz de agujerear la cabeza de un mamut, de hacer ruido y de tender emboscadas. A cada cual su terreno"
\end{abstract}

Virginie Despentes, Teoría King Kong (2006)

\section{Historia reciente y género}

En el campo de la historia argentina reciente del período 1955-1976, la relación entre género y derechas sigue siendo un área vacante. Si bien existen investigaciones sobre el rol de las mujeres en las organizaciones nacionalistas de los años ' 20 y ' 30 , las coordenadas más frecuentes de los trabajos dedicados a la segunda mitad del siglo XX giran alrededor de la militancia femenina en organizaciones guerrilleras y partidos de izquierda, la represión de la última dictadura militar, y las transformaciones de la familia, la pareja y la vida cotidiana en los años '60 y '70 (D'Antonio y Viano, 2018). ${ }^{1}$ En Europa y Estados Unidos, en cambio, los estudios de género sobre movimientos fascistas que incorporan como un eje crucial a las masculinidades, proveen un amplio repertorio de producciones (Pickering-Iazzi 1995; Mosse 1996; Woodley 2010). El propósito de este artículo es analizar las representaciones sexo-genéricas en la prensa política del Movimiento Nacionalista Tacuara (MNT), perteneciente al campo de la derecha nacionalista, y el Movimiento Nacionalista Revolucionario Tacuara (MNRT), una escisión del primero que se

\footnotetext{
1 Para los estudios de género en las organizaciones nacionalistas Mc Gee Deutsch 1993; Anchou, 2008.
} 


\section{Esteban Campos}

desplazó a posiciones lindantes con la izquierda peronista. ${ }^{2}$ A partir de la observación de periódicos como Tacuara. Vocero de la juventud nacionalista, Ofensiva, Barricada y Tacuara del manchón en los años que van entre 1958 y 1964, planteo que la construcción de estereotipos de género en la prensa de la Tacuara nacionalista y la Tacuara revolucionaria es indisociable de su discurso político. Estas referencias, aunque dispersas en la cartografía de las fuentes documentales, se repiten de manera sistemática hasta convertirse en un tópico discursivo del MNT, mientras que en los medios gráficos del MNRT ocupan un lugar marginal. En la insistencia de vincular la política con el género subyacía una práctica discursiva que exaltaba la virilidad como un atributo masculino propiamente nacionalista. Del otro lado, la oposición y sus símbolos eran ridiculizados en términos misóginos y homofóbicos.

El peso de la masculinidad en la construcción identitaria de organizaciones políticas como Tacuara, que formaron parte de sistemas sexo-genéricos históricamente situados, no ha sido tenido en cuenta por ninguna investigación. Aunque Natalie Zemon-Davies advertía a mediados de los años '70 que "no deberíamos trabajar solamente con el sexo oprimido, del mismo modo que un historiador de las clases sociales no puede centrarse por entero en los campesinos" (Andújar 2012: 97), las masculinidades siguen siendo un interés lateral en la historiografía con perspectiva de género de la Argentina. Dado que la masculinidad tacuarista se configuraba simultáneamente en estructuras de relación que iban más allá del género (Connell 1997:37), dar cuenta de estos elementos permitirá iluminar un ángulo poco transitado de las representaciones políticas sesentistas. Para Omar Acha, por ejemplo, el sexo, el deseo, la masculinidad y la feminidad son objetos de la investigación histórica irreductibles al ámbito de la historia de las mujeres y los estudios de género, ya que participan en la organización de las formas ideológicas. Como señala en uno de sus trabajos sobre la obra de Juan José Hernández Arregui:

La problematización de la diferencia sexual fue un tópico decisivo, sobre todo para definir las clasificaciones y los denuestos, enunciados en general muy rápidamente, pero que tienen la función de establecer una distinción entre un campo positivo y el otro negativo. Lo viril y penetrador caracteriza a la clase obrera, a la población nativa del interior, al nacionalismo popular, y lo femenino o andrógino a la oligarquía, a la intelectualidad extranjerizante, a la clase media urbana (...) La crítica sexual del otro había sido utilizada por el peronismo y el antiperonismo. Desde cada uno de los sectores se procedía a una denuncia pública del contrario. Ezequiel Martínez Estrada mentaba a los "escritorzuelos" peronistas como "maricones de la literatura" y Arturo Jauretche le respondía llamándolo "un manflorón, una especie de marica intelectual". La desconfianza hacia la clase media también era simbolizada con rasgos

\footnotetext{
${ }^{2}$ La categoría de sistema sexo/genéro como alternativa a los usos más ahistóricos y transculturales de la noción de Patriarcado es de la antropóloga Gayle Rubin. Para Rubin, esta clase de sistemas pueden definirse como "el conjunto de las disposiciones por las que una sociedad dada transforma la sexualidad biológica en productos de la actividad humana, más allá del modo concreto e histórico en que esas disposiciones se organicen" (Fabbri, L., 2013: 86).
} 


\section{Argentina, tierra de machos y señoras gordas. Género, masculinidad y política en Tacuara}

de género, como en la "Señora Pequeña Burguesía" que denunciaba Rodolfo Puiggrós. Aún más amplia era la presencia de la representación de la "penetración" extranjera y la "entrega" al imperialismo, y de la defensa de la integridad sexual por la clase obrera nativa (Acha 2012: 6, 15-16).

Si la introducción del sexo como una trama visible del discurso social en la Argentina se remontaba como mínimo a fines del siglo XIX, lo nuevo del ciclo peronista fue la inclusión de variables de género como parte de una saga nacional-popular, que unía a las montoneras federales con el proletariado industrial de origen provinciano. El discurso genérico del peronismo, que en buena medida compartía Tacuara, presentaba a una clase obrera nacional y masculina con amplias raíces históricas (Acha 2012: 16). Estos motivos, característicos de las mutaciones del revisionismo histórico en los años ' 50 y ' 60 , fueron un punto de confluencia entre las tradiciones de la derecha nacionalista y la cultura política de la emergente izquierda peronista.

\section{Tacuara y sus agrupaciones derivadas}

Tacuara fue una organización nacionalista y católica de notable exposición pública entre 1958 y 1964 por sus actividades antisemititas y anticomunistas, cuyos orígenes se remontan a un puñado de militantes provenientes de la Unión Nacionalista de Estudiantes Secundarios. Su ideología recorría buena parte del universo cultural de la derecha argentina y europea de entreguerras: el falangismo de José Antonio Primo de Rivera, el nacional-sindicalismo de Ramiro Ledesma Ramos, el revisionismo histórico, teóricos del antisemitismo como el padre Julio Meinvielle, e intelectuales filo-nazis como el francés Jacques-Marie de Mahieu, cuya teoría del Estado comunitario criticaba la propiedad privada y la plusvalía. En la definición de su líder Alberto Ignacio Ezcurra Uriburu, los tacuaristas no eran de izquierda ni de derecha, sino una síntesis superadora de ambas corrientes. ${ }^{3}$ Los medios de prensa de la organización que difundían éstas ideas eran Tacuara. Vocero de la juventud nacionalista, periódico oficial del MNT dirigido primero por Joe Baxter, y luego por Alberto Ignacio Ezcurra Uriburu, y Ofensiva, un boletín de circulación interna que dependía del Departamento de Formación dirigido por Rodolfo Domínguez.

En 1958, a partir de la intervención en el conflicto conocido como laica o libre a favor de la legalización de las universidades católicas, el MNT creció numéricamente y modificó su composición social. El núcleo originario, vinculado a jóvenes de familias patricias, fue desbordado por la incorporación de nuevos militantes con un perfil más plebeyo y afinidades peronistas, lo que tuvo como consecuencia varias rupturas. En octubre de 1960, un grupo cercano al padre Meinvielle se separó para

\footnotetext{
3 “Los tacuaristas no somos asesinos, afirma su jefe". Diario Crónica, 04/05/64.
} 


\section{Esteban Campos}

fundar la Guardia Restauradora Nacionalista, denunciando que Tacuara había sido conquistada por "el fidelismo, el trotskismo y el ateísmo" (Bardini, 2002: 44). Por el contrario, otros activistas que criticaban a Ezcurra Uriburu por no comprometerse a fondo con el peronismo crearon en 1961 el Movimiento Nueva Argentina, una escisión que se proclamó abiertamente peronista y se vinculó a los sindicalistas de la Unión Obrera Metalúrgica. En 1962 tuvo lugar la ruptura del Movimiento Nacionalista Revolucionario Tacuara, a partir de un grupo liderado por José Luis Nell, Joe Baxter y Alfredo Ossorio, que se acercó al peronismo con un nacionalismo más permeable a la cultura de izquierdas. El MNRT reivindicaba los procesos revolucionarios en Cuba y Argelia, leía a autores provenientes de la izquierda nacional como Jorge Abelardo Ramos, y practicaba acciones armadas de carácter expropiatorio. Esta mutación expresaba el pasaje de la ideología nacional-católica del MNT a un nacionalismo más secularizado, interesado por la emancipación económica y social del Tercer Mundo. La transformación de la Tacuara revolucionaria se puede rastrear en el periódico Tacuara. Órgano del Movimiento Nacionalista Revolucionario Tacuara, también conocido como Tacuara del Manchón por la mancha impresa sobre las primeras dos letras de la publicación. El medio de comunicación militante dirigido por Julio Ríos publicó no menos de siete números casi desconocidos en los medios académicos. ${ }^{4}$

Al poco tiempo de iniciarse el recorrido del MNRT, Ossorio y sus seguidores cuestionaron lo que veían como un giro a la izquierda del sector capitaneado por Baxter y Nell, razón que los llevo a congregarse en torno al periódico Barricada, con un discurso próximo a las ideas comunitaristas de De Mahieu. En agosto de 1963, la fracción izquierdista del MNRT asaltó el Policlínico Bancario en el barrio porteño de Caballito con un saldo de dos muertos, tres heridos y un botín de 100.000 dólares, pero al año siguiente una investigación policial desbarató a la organización. En la cárcel, un grupo de militantes de la Tacuara revolucionaria se acercó al marxismo, sin abandonar el peronismo como identidad política. Algunos, como Jorge Caffatti, Carlos Arbelos y Alfredo Roca, continuaron su militancia en las Fuerzas Armadas Peronistas (FAP). Otros, como Joe Baxter y José Luis Nell, se vincularon al Ejército Revolucionario del Pueblo y a Montoneros, respectivamente.

\section{Masculinidades}

Desde sus inicios, los jóvenes de colegios secundarios que ingresaban a Tacuara no sólo adoptaban una ideología política, sino también un conjunto de rituales, una manera de vestir y una serie de actividades que les permitían distinguirse de sus pares y del género opuesto. Como graficaba Eduardo Galeano en una nota

\footnotetext{
${ }^{4}$ Facuando Carman cita la existencia de tres ejemplares publicados entre octubre y noviembre de 1963, pero el hallazgo de un número 7 con fecha de febrero de 1964, poco antes de la dispersión del MNRT, permite suponer que hay otros números no relevados por ninguna investigación (Carman 2015).
} 


\title{
Argentina, tierra de machos y señoras gordas. Género, masculinidad y política en Tacuara
}

periodística de 1967, el MNT era un ámbito de socialización predominantemente masculino:

\begin{abstract}
Otros elementos del fetichismo fascista resplandecen en la naciente leyenda de los muchachos «de la caña», «los machos», «los que se la juegan»: el saludo con la palma extendida, las grises camisas grafa que parecen camisas militares, las ceremonias de la iniciación, la conquista del derecho a la cachiporra -goma, arena, plomo- y a las armas de fuego (Galeano 2006: 135).
\end{abstract}

Tacuara irrumpió en el escenario político como una fraternidad de varones que se peinaban hacia atrás con gomina, vestían camisa y pantalón grises, calzaban mocasiones con punta de hierro y lucían prendedores con la cruz de Malta en sus solapas (Gutman 2003: 71). Los enfrentamientos con militantes de izquierda y los atentados antisemitas eran un rito de pasaje que, para los jóvenes tacuaristas, significaban politizarse en un sentido amplio: formar parte de una organización política, saltar a la vida adulta y conquistar un reconocimiento en la esfera pública. Pero no menos importante era que la ética y la estética de poner el cuerpo en disposición de combate les permitía obtener, a través de la violencia colectiva, el dividendo patriarcal de una agresividad atribuida a los auténticos varones. ${ }^{5}$ Estas prácticas se correspondían en la prensa del MNT con un discurso que exaltaba la virilidad como una cualidad masculina que simbolizaba a la patria misma. Bárbara Spackman (1996) y Daniel Woodley (2010) sostienen que el discurso fascista realizaba una defensa exagerada de la masculinidad blanca porque estaba obsesionado con la virilidad y la fertilidad, elevadas al rango de imperativos políticos para la preservación de la raza y la nación. Si bien Tacuara había surgido al calor de la guerra fría y se filiaba con distintas tradiciones ideológicas, era deudora de las mismas concepciones, como puede verse en este largo pasaje del boletín Ofensiva:

Cuando el enemigo habla de nuestras "ceremonias secretas", de las misteriosas "eminencias grises" que rigen la "conjura nazi" a la que sirve TACUARA, está queriendo negarnos nuestra espontaneidad, el carácter de viril reacción nacional que tiene nuestra postura (...) Desde el judío Freud que, buscando la desintegración de la unidad de la familia, escupe sus asquerosas "motivaciones sexuales" sobre el amor filial; hasta el no menos judío Jacobo Timmerman que por ejemplo- en el primer número de "primera plana", tras verse obligado a reconocer que el pueblo argentino desea un gobierno autoritario, "explica" este deseo afirmando -asesorado por "eminentes" siquiatras y sociólogos- que en nuestro país más del $80 \%$ de la población sufre de paranoia, ezquizofrenia o por

\footnotetext{
${ }^{5}$ La noción de dividendo patriarcal se refiere a los beneficios que la totalidad de los varones obtienen de la masculinidad hegemónica, "sin las tensiones o riesgos de ser la prmera línea del patriarcado", o sea, sin necesidad de compartir el ejercicio de formas de dominación sobre la mujer basadas en la violencia y la brutalidad (Connell 1997:41-42). Sobre masculinidades (Maristany y Peralta 2017; Viveros Vigoya 1997; Martini 2002)
} 


\section{Esteban Campos}

lo menos neurosis... El enemigo busca afanosamente crear una desconfianza interna en la propia capacidad de reacción. No existe dignidad, no existe amor, no existe fidelidad, no existe patriotismo: todo se reduce a un par de instintos simiescos, a varias subconscientes desviaciones sexuales y a un absoluto materialismo dialéctico. Frente a esta rastrera concepción de vida, verdadera castración espiritual del ser humano, debemos alzar en toda su violencia nuestra espontaneidad nacionalista. 6

Para el "Camarada N." que firmaba la nota, Tacuara representaba la virilidad, la humanidad y la nación, mientras que el psicoanálisis freudiano, el materialismo dialéctico y el judaísmo eran parte de una amenaza multiforme que pretendía reducir las instituciones básicas de la nacionalidad a pulsiones animales y desviaciones sexuales. La figura de la castración, para analistas del fascismo como Klaus Theweleit, proviene de un primario temor de los varones a perder la identidad de género, en otras palabras el riesgo a la disolución de la diferencia sexual y las jerarquías entre varones y mujeres (Woodley, 2010: 218-219). En los propios términos del MNT, la negación de la virilidad era también una castración política, la posibilidad de que judíos y comunistas tomen el poder para destruir la familia, la patria, y todo aquello que distinguía la identidad tacuarista. El tópico de la virilidad también aparece en la prensa oficial de Tacuara: en un artículo sobre el nacionalsindicalismo, Adolfo López Portillo sostenía que "Las Fuerzas Armadas no pueden estar ausentes de la lucha de un país hecho a Cruz y Espada que se apresta, viril, militarmente, a encarar la batalla final". ${ }^{7}$ En otro número de Tacuara. Vocero de la Juventud Nacionalista, E. T. Bustamante le dedicaba un poema a Darwin Passaponti, donde lo ensalzaba en estos términos "Tu juventud vibrante supo ver el camino / y ya no eras un soldado de nuestra Patria erguida / viril adolescente que, en heroico destino / casi sin conocerla supiste dar la vida". ${ }^{8}$

En el discurso del MNT, la virilidad como atributo de la nación y los nacionalistas se asociaba a otras figuras de carácter fálico que, aparte de exaltar la masculinidad, concentraban "todas las fantasías colectivas de la fuerza fundadora" (Bourdieu 2010:15). La idea de la "Patria erguida" no era casual ni aislada; en una nota de corte historiográfico revisionista para el boletín Ofensiva, Mariano Laura se preguntaba que quedaba del ejemplo soberanista de José de San Martín y Juan Manuel de Rosas:

¿Qué hay de todo esto en la actualidad? ¿Qué hay de ese fervor nacionalista que impulsa a San Martín a transponer los Andes? ¿Qué hay de ese ardiente Nacionalismo que hace el milagro de la Vuelta de Obligado o sea el triunfo sobre

\footnotetext{
${ }^{6}$ Cda. N., "Sobre la espontaneidad y la improvisación", en Ofensiva n. 12 (diciembre de 1962), p. 2.

7 López Portillo, Adolfo, "Nacionalsindicalismo", en Tacuara. Vocero de la Juventud Nacionalista, año XV, n.9 (1960), p. 2.

8 E. T. Bustamante, "Darwin Passaponti", en Tacuara. Vocero de la Juventud Nacionalista s/n (noviembre de 1963), p.1. Darwin Passaponti (1927-1945) fue un militante de la Unión Nacionalista de Estudiantes Secundarios, que murió a causa de un disparo en la cabeza frente al diario Crítica durante la desconcentración de la manifestación del 17 de octubre de 1945. Por esta razón, es reivindicado como mártir por nacionalistas y peronistas.
} 


\section{Argentina, tierra de machos y señoras gordas. Género, masculinidad y política en Tacuara}

las potencias de la época, cuando apenas la República Argentina era una decena de aldeas rudimentarias? ¿Qué queda de aquellos sacudimientos nacionales cuando el gauchaje enardecido ante la presencia del Caudillo, irrumpía en la Plaza de la Victoria, y arrastraba tirando de las varas y de las lanzas, el carruaje del Gaucho Rubio, en un delirio multitudinario, hasta la Casa de Gobierno? ¿Qué queda de aquella Argentina vertical, dispuesta a jugarse, de aquella Argentina erecta, permanente vigía y celosa defensora de hispanoamérica? ${ }^{9}$

La figura de la nación erecta se correspondía con la imagen de la caña como sinécdoque de Tacuara y metáfora de virilidad en cuanto potencia asociada al género masculino. ${ }^{10}$ En el número 7 de Tacuara. Vocero de la Juventud Nacionalista, una nota sin firma reivindicaba que "todavía existe en Argentina una juventud dispuesta a dar su sangre por esta tierra, tierra de machos, curtida por el sudor y la sangre de nuestras generaciones gauchas, soberana a punta de lanza tacuara". ${ }^{11}$ La masculinidad hegemónica reverberaba en las gestas pasadas y en las necesidades presentes de la nación argentina, como advertía el “camarada A.I.E” (Alberto Ignacio Ezcurra) en Ofensiva: "a la Patria no se la defiende con papeletas, sino con tacuaras, cadenas y cañones viejos, con piedras o con aceite hirviendo (...) en lugar de tanto palabrerío democrático y tanta imbecilidad liberal, hace falta la mano fuerte de un hombre macho, de un caudillo criollo".12

Dado que el fascismo politizaba la virilidad y la fertilidad, por la misma razón atacaba cualquier forma de afeminación y homosexualidad como corruptores de la integridad de la nación y la raza. La homofobia fascista nacía de una tensión entre la hipermasculinidad que exaltaba la camaradería del soldado varón alejado de la heterosexualidad doméstica y la represión a las tendencias homosexuales en la comunidad guerrera idealizada (Mosse 1996:175; Woodley 2010:212). El discurso del MNT manifestaba aversión por lo que concebía como desviaciones y desbordes sexuales, que también aparecían asociados a los extravíos propiamente políticos. En consecuencia, el reverso de la masculinidad y la virilidad tacuarista era una retórica cargada de elementos homofóbicos y misóginos que proveían a Tacuara de contratipos, un grupo de imágenes contrarias que reflejaban la propia identidad (Mosse 1996:56-57). Los contratipos podían ser utilizados tanto para desacreditar opositores políticos como con fines político-asociativos, una marca de manada destinada a proteger la homosocialidad dominante de la agrupación. Tal como indica Raewyn Connell, la masculinidad hegemónica opera en "como los hombres difieren entre ellos", es decir, apunta a la diferenciación interna de los varones de la misma manera que las prácticas de la feminidad jerarquizan a las mujeres (Connell,

\footnotetext{
9 Mariano Laura, “San Martín, Rosas y la soberanía”, en Ofensiva n. 11 (noviembre de 1962), pp. 1517.

10 Uno de los símbolos del MNT era una lanza fabricada con el asta de una tacuara, planta de la familia del bambú que crece en la Argentina y otros países latinoamericanos. En la narrativa del revisionismo histórico, las tacuaras eran uno de los signos distintivos de las montoneras federales del siglo XIX.

11 "Esto es un sainete" (s/f), en Tacuara. Vocero de la Juventud Nacionalista n.7 (1959), p. 3.

${ }^{12}$ Camarada A.I.E., “Soberanía o muerte”, en Ofensiva n. 11 (noviembre de 1962), p. 11.
} 


\section{Esteban Campos}

1997: 17). En el artículo "Sobre la camaradería”, que procuraba intervenir en la vida cotidiana de la organización, se argumentaba que todas las derrotas del nacionalismo provenían de fallas en la solidaridad grupal. La camaradería "es algo más que palmearse la espalda y preguntarse por la familia, luego de haberse saludado brazo en alto", ya que implicaba sacrificio, caballerosidad y entrega al movimiento, pero sobre todo sinceridad en el compromiso individual y colectivo:

Sinceridad por los camaradas en la vida diaria. Entre nosotros no caben espíritus cobardes, invertidos espirituales, que hacen de la calumnia rastrera, de la maledicencia, de la crítica sucia, de la disconformidad injustificada, sus temas de conversación habituales. Afrontamos al enemigo de frente, y de frente -por las vías que la disciplina marca- presentamos nuestras quejas cuando sinceramente creemos que son justificadas. Ejercitamos la camaradería y repudiamos la "camarilladería".13

La conducta desviada en el seno de Tacuara era metaforizada con la figura del invertido, por naturaleza cobarde y rastrero. En cambio, el buen militante nacionalista acometía al enemigo de frente, lo que desalentaba -filas adentro de la organización- cualquier posibilidad de ofensa por detrás que pusiera en riesgo las vías rectales simbólicas de los camaradas. La transgresión sexual, desde luego, también era incluida en la trama densa de la conspiración opositora. Para Ezcurra Uriburu, "el materialismo histórico, la economía liberal, el sufragio universal, pueden ser defendidos por un criminal, un estafador o un invertido sin otra condición que la elocuencia verbal o escrita". ${ }^{14}$ En palabras del dirigente, el militante ideal era mitad monje mitad soldado, y debía entregarse de manera desinteresada por "multitudes que sólo pensaban en la plata, en las mujeres y en el fútbol, para quienes la patria, el espíritu y su propio sacrificio eran una estupidez". ${ }^{15}$ La crítica puritana al aburguesamiento de la sociedad argentina era parte de una cosmovisión donde el desorden sexual se emparentaba al desorden político. Esto puede verse en otra nota firmada por el jefe del MNT, donde denunciaba a Arturo Frondizi por generar las condiciones para que las protestas contra su gobierno fueran capitalizadas por el comunismo. El oficialismo y sus aliados:

Quieren apurar hasta la última copa, quitarle al país la última gota de sangre y jugo, hasta que el amanecer de la Revolución corte violentamente esta noche postrera de orgías. Un corte total y a empezar de nuevo. Con nuevos hombres, nuevas instituciones y nuevas guías. Un Nuevo Orden frente al viejo caos. ${ }^{16}$

\footnotetext{
${ }^{13}$ Camarada N., "Sobre la camaradería", en Ofensiva n. 11 (noviembre de 1962), pp. 1-3.

14 Alberto Ignacio Ezcurra Uriburu, "Estilo", en Tacuara. Vocero de la Juventud Nacionalista n.9 (1960), p. 2.

15 Ibidem.

${ }^{16}$ Alberto Ignacio Ezcurra Uriburu, "Carnaval de entrega", en Tacuara. Vocero de la Juventud Nacionalista n.8 (1960), pp. 1-2.
} 


\title{
Argentina, tierra de machos y señoras gordas. Género, masculinidad y política en Tacuara
}

Las analogías entre sexo y política no eran sólo un capricho de Ezcurra Uriburu. En el boletín Ofensiva, Pedro Otaño redactó un extenso descargo sobre el "Diálogo con los jóvenes fascistas" publicado por Rogelio García Lupo, una investigación periodística que advertía coincidencias entre el tacuarismo y el castrismo. Para el militante de Tacuara la comparación era falsa, puesto que la Revolución cubana carecía de sentido cristiano y nacional. Por el contrario, con la llegada de Fidel Castro: "La explotación capitalista un tanto anárquica, dio una vuelta más al torniquete con la economía colectivista. El jolgorio de los cabarets y de los prostíbulos halló su sucedáneo masivo en los campamentos de camaradería y en el amor libre". ${ }^{17}$ Una vez más, la enunciación de la diferencia sexual y sus ansiedades alrededor de la desviación y el desborde servían para recortar las identidades políticas, para señalar la escisión entre un "nosotros" y un "ellos".

\section{Feminidades}

El Movimiento Nacionalista Tacuara no fue una organización exclusivamente masculina, si bien las mujeres ocupaban un lugar claramente minoritario en él. El dirigente Oscar Denovi, por ejemplo, recuerda que su esposa lo acompañaba a todos los actos de la agrupación, y además participó como candidata a concejal en 1962 por la Unión Cívica Nacionalista, un partido político que le permitía a Tacuara promocionarse electoralmente (Padrón2017:282). Sin embargo, para comprobar una participación más orgánica de las mujeres hay que indagar en la prensa del Movimiento Nacionalista Revolucionario Tacuara: el 17 de agosto de 1964 se realizó un acto en conmemoración de José de San Martín en Goya, Corrientes, donde "hicieron uso de la palabra el Cda. secretario general del Comando 'San Martín' de TACUARA y la Cda. Jefa de las Brigadas Femeninas del MNRT de dicha localidad". ${ }^{18}$ Hasta ese momento, la política tacuarista parecía ser cosa de hombres, como se advierte en otro testimonio de Denovi:

\begin{abstract}
Nosotros cuando nos enfrentábamos a los comunistas, que tuvimos dos en la calle Lavalle, que los comunistas venían en manifestación, entonces salimos nosotros: “Viva Tacuara” y qué sé yo, y había mujeres, y me acuerdo que Horacio Bonfanti dijo: "Las mujeres afuera", y ahí empezamos a las piñas con los tipos...(Padrón2017:240)
\end{abstract}

Las mujeres eran excluidas de aquellas prácticas de "poner el cuerpo" que simbolizaban el compromiso militante del MNT y se vinculaban a una sociabilidad predominantemente masculina. Una de las formas en que la prensa tacuarista percibía los roles de género se expresaba de manera tradicional, naturalizando la diferencia sexual y preservando discrecionalmente las fronteras simbólicas entre lo masculino y lo femenino. En dicha grilla clasificatoria, un primer fenómeno a señalar

\footnotetext{
17 Otaño, Pedro, "Los jóvenes fascistas", en Ofensiva n. 9 (agosto de 1962), pp. 1-3

18“Reseña de actos", Barricada n.8 (c. diciembre 1964) s/p
} 


\section{Esteban Campos}

es la exaltación de la maternidad, como puede verse en el poema "Salutación de una esperanza madre":

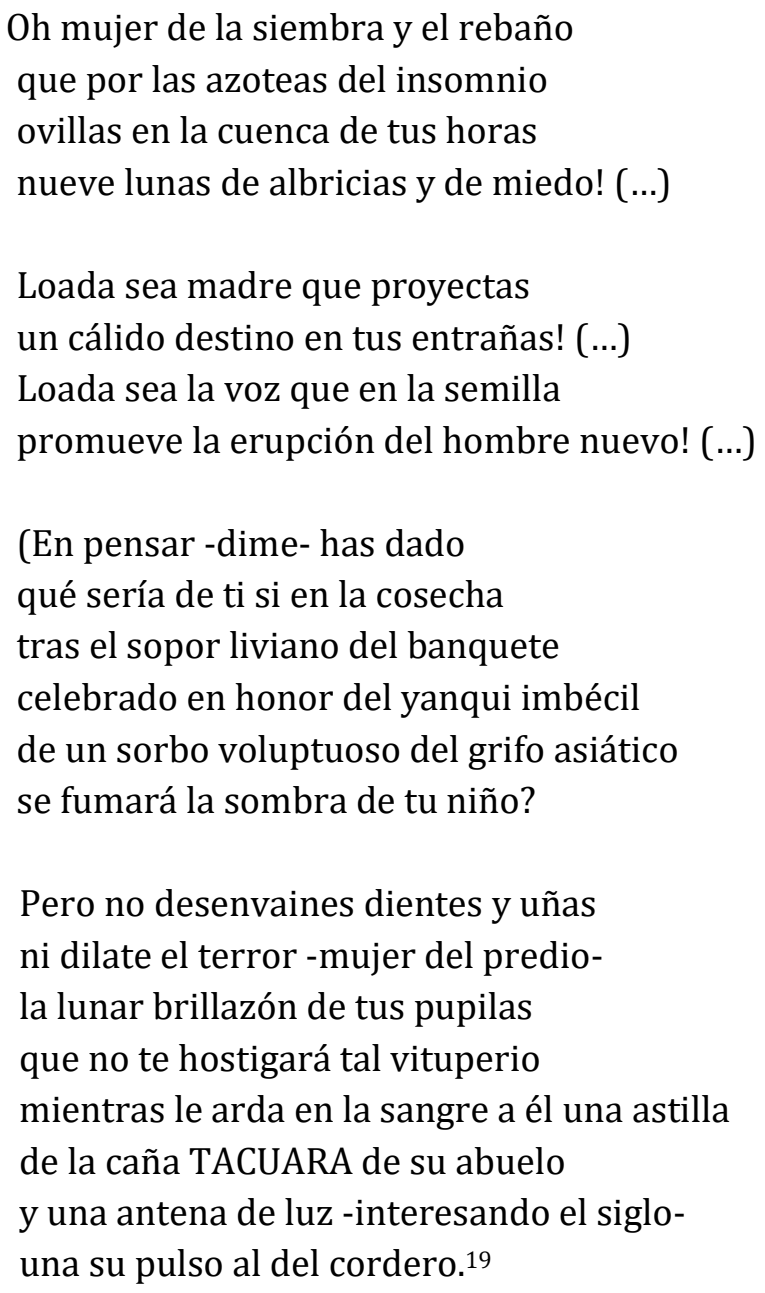

En los sinuosos versos de Soulé Tonelli, las mujeres eran valoradas por su lugar en la reproducción de sujetos revolucionarios, mientras lo público, lo político y la potencia fálica aparecían asociados al género masculino. Frente a la amenaza conjunta del capitalismo norteamericano y el comunismo soviético -el "yanqui imbécil" y el "grifo asiático"- no hacía falta que la madre ejerciera algún tipo de resistencia. Su prole de hombres nuevos estarían allí para defenderla, híbridos de tradición (la caña tacuara del abuelo montonero) y modernidad (la antena de luz como signo poético futurista). Por otra parte, un rastreo atento de la prensa de Tacuara indica que el otorgamiento de atributos femeninos era casi siempre negativo:

Somos asimismo espectadores de los chillidos de señoras de ambos sexos por la magnifica 'Semana Social' de la Iglesia, en un clarísimo intento por escindir al pueblo de la fe católica y arrojarlo en brazos de las "corrientes democráticas",

${ }^{19}$ Héctor Pedro Soulé Tonelli, “Salutación a una esperanza madre”, en Ofensiva (s/n), p. 3. 


\section{Argentina, tierra de machos y señoras gordas. Género, masculinidad y política en Tacuara}

que no es en nuestro caso otra cosa que el materialismo liberal-comunista. ${ }^{20}$

La representación de la feminidad era empleada como un arma para clasificar y denigrar a liberales, demócratas e izquierdistas. Pero la práctica discursiva que, al ser repetida de manera sistemática, se convirtió en un tópico de la prensa tacuarista fue la de feminizar al régimen democrático liberal. En "Carnaval de entrega", la editorial redactada por Ezcurra Uriburu, el principal dirigente del MNT sostenía que:

La vieja del gorro frigio, hija de la revolución francesa y señora del país desde Caseros, está en las últimas: chochea. Y nuestra pobre Patria, nacida para grandes destinos en frustración constante, corcovea para sacarse de encima a esta gorda caduca, que con las riendas en la mano le está haciendo hacer piruetas de locura. Porque esto que estamos presenciando, que son los estertores de un régimen decadente, la democracia liberal, de instituciones, hombres, parlamentos y partidos de un régimen de supervivientes, tiene todas las características de un circo y un sainete. ${ }^{21}$

Si en la misma tapa del periódico donde fue publicado este fragmento, la patria aparecía retratada como una joven guerrera de casco con penacho, que portaba una bandera argentina con una cruz de Malta en el centro, la democracia también tenía cara de mujer, pero era vieja y gorda. En otra nota se graficaba más la imagen y se añadían nuevos elementos: "No nos importa -lo repetimos una vez más- la suerte de la democracia (esa señora gorda, mal vestida y que tiene acento extranjero). Nos importa la patria, nuestra patria, la que los políticos nos niegan". ${ }^{22}$ En distintos ejemplares de la prensa tacuarista también se pueden ver diatribas contra "el grotesco general Aramburu, nuevo Mitre de las señoras gordas" y contra La Nación, "el diario de las señoras gordas"23, lo que permite inferir que el tópico misógino no sólo tenía un contenido político sino también sociológico, ya que servía para denostar a las clases altas etiquetadas como oligarcas.

La feminización de los adversarios políticos y sociales también fue una estrategia retórica visible, aunque en menor medida, en la prensa de la Tacuara revolucionaria, tanto la del sector que respondía a Alfredo Ossorio como la fracción vinculada a Joe Baxter y José Luis Nell. En septiembre de 1964, Barricada denunció al gobierno de Arturo Illia por clausurar la imprenta y encarcelar al equipo editorial del periódico, en el marco de la ola de detenciones por el asalto al Policlínico Bancario:

\footnotetext{
20 Adolfo Pérez Portillo, "Nacional-sindicalismo", en Tacuara. Vocero de la juventud nacionalista. Año XV, n. 9, 1960, pp. 1-2.

${ }^{21}$ Alberto Ignacio Ezcurra Uriburu, “Carnaval...”, Op. cit., pp. 1-2.

22 “Que queremos los nacionalistas?” (s/f), en Tacuara. Vocero de la juventud nacionalista, Año XIV, n.7, 1959 , p. 3.

23 "Comentarios" (s/f), en Tacuara. Vocero de la juventud nacionalista, Año XV, n. 9, 1960, p. 2 y Ricardo Aravac, "La Nación insulta al movimiento obrero", en Tacuara. Vocero de la juventud nacionalista. Año XVIII, s/n, 1963, p. 2.
} 


\section{Esteban Campos}

Todos los resortes y engranajes del sistema se movieron y coincidieron (como siempre) ante el peligro. Desde el siempre útil Alfredo Palacios y el marxista Codovilla, que pedían con histeria femenina la "cárcel para los asesinos fascistas", hasta los sectores ultra-gorilas del gobierno que denunciaron la "insurrección nacionalista. ${ }^{24}$

El desorden mental, que para los editores de Barricada se podía asociar con naturalidad a la condición femenina, de nuevo era utilizado como atributo negativo para desacreditar facciones rivales. Esta peculiar variante de misoginia transferida al campo político-partidario se repite más abajo: "Sepan el régimen y sus mucamas que la virulencia de sus represiones registran como un termómetro el final de su dominio". El trabajo doméstico asalariado ejecutado por mujeres era una metáfora de la servidumbre, que servía para descalificar a los sectores señalados por el MNRT-Ossorio como cómplices del gobierno radical. La continuidad con los modelos retóricos de la Tacuara nacionalista es palpable: en una editorial para conmemorar el 17 de octubre de 1945, Alberto Redrueyo reivindicaba a "la raza nativa, el 'cabecita negra'", y afirmaba que "Los núcleos sudorosos y mugrientos de tierra argentina, portadores de rebeldía nacional, salpicaban el barro gaucho a los azorados rostros de las 'gordas de la oligarquía'". ${ }^{25}$ La clase alta era rebajada a través de la doble mácula de la feminización y la salpicadura de barro, una degradación grotesca relacionada a lo inferior corporal de larga data en la historia de la cultura (Bajtín 2003:117). La prensa del sector Baxter-Nell del MNRT, por último, consideraba que la persecución policial contra los nacionalistas era una manifestación de la "impotencia histórica del régimen colonial", y advertía: "sabemos que detrás de los aullidos de las Señoras Gordas, está presente la presión social de los trabajadores"26. Aún así, las referencias de género y sexualidades en la prensa del MNRT son relativamente marginales, si las comparamos a las citas del MNT: mientras en Tacuara del Manchón hay una sola mención, y en Barricada dos, entre Tacuara. Vocero de la Juventud Nacionalista y Ofensiva suman dieciseis intervenciones.

La concurrencia de adversarios políticos, régimen parlamentarista y clases altas en el tropo de la señora gorda, no era la única forma de enlazar el género femenino con las prácticas políticas. La democracia también podía ser una mujer malvada, traicionera y prostibularia, como se puede observar en una editorial de Tacuara. Vocero de la Juventud Nacionalista. Allí se narraba la historia de un hombre que era engañado por su esposa, y no podía remediar la situación por más que fijara

\footnotetext{
24 "Nuevamente en la calle" (s/f), Barricada. Órgano del Movimiento Nacionalista Revolucionario Tacuara, Año II, n.7 (septiembre de 1964), p. 2.

25 Alberto Redrueyo, "Lealtad al 17", en Barricada del nacionalismo revolucionario. Órgano del Movimiento Nacionalista Revolucionario Tacuara n. 2 (noviembre de 1963), p. 1.

26 "Represión. Ricardo Polidoro, víctima de la legislación oligárquica” (s/f), en Tacuara del manchón (octubre de 1963), p. 1.
} 


\title{
Argentina, tierra de machos y señoras gordas. Género, masculinidad y política en Tacuara
}

residencia en distintos lugares. La moraleja, para la pedagogía tacuarista, era que había que cambiar de mujer y no de barrio, como ocurría con la política doméstica:

\begin{abstract}
La anécdota es real, que le vamos a hacer. A nosotros nos casaron, después de Caseros, con la Democracia. Nos casaron por la fuerza, y el matrimonio es inválido, y desde hace cien años la democracia nos viene engañando y estafando, y nos está conduciendo a la ruina. Y nosotros, como el hombre del cuento, insistimos en mudar de barrio, es decir, saltamos de un partido a otro, de los radicales a los conservadores, a los socialistas, a otros radicales, incapaces de una solución concisa y violenta que mande al diablo de una vez por todas a esta ramera envejecida que en mala hora nos endilgaron por compañera. $^{27}$
\end{abstract}

Para la prensa del MNT, la democracia era una prostituta que engañaba a la patria, imaginada como un varón traicionado e impotente. En otro número del mismo periódico se empleó una alegoría similar para definir la asunción de Arturo Illia como presidente de la nación en octubre de 1963: "es como cuando una mujer de la que uno está enamorado se casó con otro. Uno no puede menos que desearle buena suerte, aunque en el fondo sabemos que no va a ser así". ${ }^{28}$ La democracia, en esta ocasión, era una mujer adúltera y la patria un marido maltratado. Si la nación argentina era exaltada como una "tierra de machos", aquí es posible advertir que también podía ser representada como un varón despojado de sus atributos viriles. Una nota disonante en la repetición de tropos misóginos es la "Carta abierta a la dama dragón", que apareció en noviembre de 1963 en la prensa de la Tacuara nacionalista. La nota era un mensaje imaginario dirigido a la "señora de Nhu", viuda del dirigente vietnamita Ngo Dinh Nhu y su cuñado Ngo Dinh Diem, presidente católico de Vietnam del Sur que fue asesinado tras intentar limitar la presencia norteamericana en la región. Estos acontecimientos habían ocurrido mientras el personaje, que no aparece citado en la nota con nombre propio, se encontraba en una gira diplomática por los Estados Unidos. Se trataba, para la prensa tacuarista, de "una dura misión para cualquier hombre, y mucho más para una débil mujer", que se había comportado de manera ejemplar al criticar en severos términos al embajador estadounidense de Vietnam del Sur. Por esta razón, era un modelo a imitar por otras mujeres afines a la ideología que predicaba Tacuara:

Pero no es la única lección que usted, señora de Nhu, ha dado con su conducta.

Porque también les ha enseñado a muchas esposas de pretendidos nacionalistas

\footnotetext{
27 "La democracia no sirve" (s/f), en Tacuara. Vocero de la juventud nacionalista, Año XVIII, s/n, (c. diciembre de 1963), p.1. La relación entre prostitución, venalidad y corrupción de la democracia también aparece en una nota de Joe Baxter en su etapa como lugarteniente de Ezcurra Uriburu en el MNT. Allí denunciaba la traición de sectores de las Fuerzas Armadas, y les exigía "que se encierren en un prostíbulo", v. J. J. Baxter, “Basta!!", en Tacuara. Vocero de la juventud nacionalista, Año XV, n. 8 (1960), p. 2.

28 "Comenzó la Illiada" (s/f), en Tacuara. Vocero de la Juventud Nacionalista, Año XVIII, s/n. (noviembre de 1963), p. 1.
} 


\section{Esteban Campos}

y católicos y anticomunistas cómo debe comportarse una mujer cuando las circunstancias lo exigen. Usted no ha querido "ayudar" a su esposo organizando "fiestas de beneficencia" o "colaborando con la parroquia de su barrio". Usted ha salido al campo de batalla, a ese áspero y cruel campo de batalla de la opinión pública, a combatir con las armas que estaban a su alcance: con su inteligencia, con su lealtad, con su belleza también. Porque más digno es usar la belleza como argumento para defender la verdad, que emplearla haciéndose tomar fotos en fiestas de sociedad. ${ }^{29}$

Como hemos visto, el fascismo tenía una obsesión con la virilidad que politizaba las relaciones de género. Para Bárbara Spackman (1995:108-109; 1996: 17-19), "en el discurso fascista el género y el sexo no se mezclan ni se emparejan: la virilidad es la propiedad del hombre, y la feminidad la propiedad de la mujer". Esta era una respuesta a la crisis de la masculinidad provocada por la modernidad capitalista de la Belle Époque, que desde una perspectiva conservadora abolía las fronteras entre los géneros, las clases sociales y las naciones (Mosse 1997:77-106). Sin embargo, llevado a su extremo, el discurso hipermasculino de la virilidad producía efectos paradójicos, ya que podía subvertir los roles fijos de género atribuidos por la sociedad burguesa. En efecto, para intelectuales vinculados al fascismo como Gabriele D'Annunzio y Teresa Labriola, el sujeto de la virilidad podía ser masculino o femenino indistintamente (Spackman 1996:17). Las representaciones tacuaristas de la "dama dragón" se debatían entre las dos inclinaciones de las virilidades fascistas: por un lado, el género femenino era naturalmente débil y la "señora de Nhu" sólo adquiría relevancia en cuanto viuda del dirigente asesinado. Por el otro, la virilidad era un atributo universal que le había permitido intervenir en la esfera pública con inteligencia, poniendo su belleza (la belleza femenina medida por el ojo del varón heterosexual) al servicio de una causa política.

\section{Consideraciones finales}

La mañana del 30 de noviembre de 1962, un grupo de alumnas de la Escuela Normal n. 2 de La Plata se encontraba limpiando el frente del establecimiento educativo, que había sido cubierto de pintadas por militantes del MNT. El conflicto se desató cuando llegaron al lugar varios miembros de "la caña", tiraron los baldes con agua que utilizaban las chicas y uno de los tacuaristas agredió a una estudiante. Según cuenta la crónica del diario El Plata, las jóvenes reaccionaron y "se lanzaron sobre él con baldes y escobas, para vengar la ofensa. El 'hombre' no encontró otra alternativa que salir corriendo, perseguido por las chicas, por la diagonal 78". ${ }^{30}$ Una primera constatación general que permite ilustrar este episodio es que no siempre los mandatos pueden ser cumplimentados. En consecuencia, las formas del discurso

29 "Carta abierta a la dama dragón" (s/f), en Tacuara. Vocero de la Juventud Nacionalista, Año XVIII, s/n. (noviembre de 1963), p. 2.

30 "Tacuara en retirada", El Plata, 30/11/62, Comisión Provincial por la Memoria, Archivo de la Dirección de Inteligencia de la Provincia de Buenos Aires (DIPBA), folio 238. 


\section{Argentina, tierra de machos y señoras gordas. Género, masculinidad y política en Tacuara}

tacuarista sobre las masculinidades y las feminidades que he tratado de relevar en este trabajo pueden ser vistas como normas sin codificar, como diseños de una subjetividad política, pero de ninguna manera como una práctica arraigada y monolítica.

El discurso de Tacuara y sus agrupaciones derivadas sobre los géneros estaba asociado a la construcción de masculinidades hegemónicas, ya que su función primordial era cohesionar a aquella fraternidad de varones de gestos marciales y cabellos disciplinados por el gel. Así cobraba sentido una faceta del discurso de la virilidad: obtener el carnet de afiliado al MNT era formar parte de una legión de militantes nacionalistas que empleaba la violencia como un medio para hacer política, pero también como un mecanismo de diferenciación entre miembros del mismo género. En consecuencia, las imágenes fálicas de la caña tacuara, la patria erguida, la nación erecta y la exaltación de la masculinidad centrada en la figura del "caudillo macho", lo mismo que la condena homofóbica al "invertido espiritual", servían para cerrar filas, establecer un modelo de camaradería ejemplar y consolidar una identidad colectiva. Con esto no quiero decir que estas formas discursivas intervenían exclusivamente en un nivel organizacional o ideológico, como códigos de comportamiento o valores alejados de la práctica política. En la prensa tacuarista se politizaba el género y el sexo, de la misma manera en que la política era sexualizada a través de los estereotipos de género. La prostitución y el amor libre se correspondían con el capitalismo y el colectivismo, mientras que lo percibido como desórdenes y desviaciones sexuales era concomitante a los desbordes políticos.

La dimensión política-partidaria de las cuestiones de género en Tacuara se pone de relieve en su tratamiento de las feminidades. Siguiendo una tradición que provenía del enfrentamiento entre peronistas y antiperonistas, pero hundía sus raíces en las preocupaciones decimonónicas alrededor de la urbanización, la inmigración y la sexualidad, la prensa del MNT y del MNRT empleó tópicos misóginos como parte de un catálogo de invectivas para diferenciar amigos y enemigos. Si la nación argentina o la clase obrera reunían todas las cualidades de la virilidad, por el contrario el régimen democrático-liberal, la oligarquía y otros sectores políticos fueron desacreditados a través de su feminización. El vehículo de esta estrategia retórica fue el tópico de la señora gorda, y la más temida figura de la prostituta/mujer adúltera, capaz de despojar a la patria de sus imaginarios atributos varoniles. Por último, en la "Carta abierta a la mujer dragón" podemos ver una aproximación diferente a la cuestión del género, ya que la construcción simbólica de la "señora de Nhu" exhibía una tensión entre los estereotipos tradicionales del género femenino y la reivindicación de una virilidad universal, que podía ser también el atributo de una mujer.

Como puede verse, en el discurso tacuarista la masculinidad y la feminidad no eran compartimentos estancos, ya que "la exaltación de los valores masculinos tiene su tenebrosa contrapartida en los miedos y angustias que suscita la feminidad" (Bourdieu 2010:76). Estos valores, como parte de un sistema sexo-genérico 


\section{Esteban Campos}

históricamente situado, no eran patrimonio exclusivo de la derecha nacionalista, ni pueden ser clasificados de manera rígida como antecedentes de un "bloqueo tradicionalista" que se impondría con el golpe militar de Juan Carlos Onganía (Terán 1993). Por el contrario, formaban parte de los prejuicios que compartía buena parte de la sociedad argentina a comienzos de la década de 1960. El país, comparado con las naciones capitalistas más avanzadas, experimentaba en aquella época una revolución sexual discreta y una emancipación femenina moderada, procesos que encontraron una férrea resistencia por parte de grupos de presión conservadores con acceso a las esferas de poder (Cosse 2009; Manzano 2017). El diario El Plata, que se había burlado de los jóvenes del MNT por emprender la retirada frente a las estudiantes platenses, definía a los militantes nacionalistas como "pesados con melenas femeninas y vestimenta con saco de cuatro tajitos". ${ }^{31}$ Sería imprudente archivar la masculinidad tacuarista y su discurso de género en un inventario de excepcionalidades militantes, o segregarla como el producto de una minoría extravagante. Por el contrario, este pequeño capítulo en la historia de la cultura política de los años '60 nos dice algo acerca de cómo somos los argentinos.

\section{Bibliografía}

Acha, O. (2012). “Juan José Hernández Arregui: historia de las ideas y sexología política”. Revista de Historia, UNComahue, № 13, pp. 1-18.

Anchou, A. (2008). Guardianas. Las mujeres de Guardia de Hierro. Imago Mundi: Buenos Aires

Andújar, A. (2012). "El Género de la Historia: aportes y desafíos para el estudio del pasado". En Cristina Viano (ed.), Miradas sobre la Historia. Fragmentos de un recorrido. Prohistoria: Rosario.

Bajtín, M. (2003). La cultura popular en la Edad Media y el Renacimiento. El contexto de Francois Rabelais. Alianza Editorial: Madrid.

Bardini, R. (2002). Tacuara. La pólvora y la sangre. Océano: México.

Bourdieu, P. (2010). La dominación masculina y otros ensayos. Anagrama-Página 12:

\footnotetext{
31"Tacuara en... Op. cit.
} 


\section{Argentina, tierra de machos y señoras gordas. Género, masculinidad y política en Tacuara}

Buenos Aires.

Carman, F. (2015). El poder de la palabra escrita. Revistas y periódicos argentinos (1955-1976). Biblioteca Nacional: Buenos Aires.

Connell, R. (1997). "La organización social de la masculinidad". En Valdés, T. y Olavarría, J. (eds.), Masculinidad/es. Poder y crisis. Isis Internacional: Santiago de Chile.

Cosse, I. (2009). “Los nuevos prototipos en los años 60 y 70: de la mujer doméstica a la joven 'liberada'. En Andújar, A., D'Antonio, D., Gil Lozano, F., Grammatico K. y Rosa, M., De minifaldas, militancias y revoluciones. Exploraciones sobre los 70 en la Argentina. Ediciones Luxemburgo: Buenos Aires.

D'Antonio, D. y Viano, C. (2018). “A propósito de la Historia Reciente, la Historia de las Mujeres y los estudios de género: intersecciones y desafíos”. En Águila, G., Luciani, L., Seminara, L. y Viano, C., La historia reciente en Argentina. Imago Mundi: Buenos Aires.

Fabbri, L. (2013). Apuntes sobre feminismo y construcción de poder popular. Puño y Letra: Rosario.

Galeano, E. (2006). "Los jóvenes fascistas descubren su país". En Nosotros decimos no. Crónicas (1963-1988). Siglo XXI: Madrid.

Gutman, D. (2003). Tacuara. Historia de la primera guerrilla urbana argentina. Vergara: Buenos Aires.

Manzano, V. (2017). La era de la juventud en Argentina. Cultura, política y sexualidad desde Perón hasta Videla. Fondo de Cultura Económica: Buenos Aires.

Maristany, J. y Peralta, J. Cuerpos minados. Masculinidades en Argentina., EDULP:La Plata.

Martini, N. (2002). “Los estudios de masculinidad”. En Estudios Sociológicos n. 20, El Colegio de México, pp. 715-732.

Mc Gee Deutsch, S. (1993). "La mujer y la derecha en Argentina, Brasil y Chile, 19001940”. En Barrancos, D. Historia y género. CEAL: Buenos Aires.

Mosse, G. (1996). The image of man. The creation of modern masculinity., Oxford University Press: Nueva York.

Padrón, J. M. (2017). ;Ni yankis ni marxistas!, nacionalistas. Nacionalismo, militancia y violencia política. El caso del Movimiento Nacionalista Tacuara., UNSAM-UNGS: Buenos Aires. 


\section{Esteban Campos}

Pickering-Iazzi, R. (ed.) (1995). Mothers of Invention. Woman, Italian Fascism and Culture., University of Minessota Press: Minneapolis.

Spackman, B. (1995). "Fascist woman and the rethoric of virility". En Pickering-Iazzi R. (ed.), Mothers of invention. Woman, italian Fascism, and Culture.. University of Minessota Press: Mineapolis.

Spackman, B. (1996). Fascist virilities. Rethoric, ideology and social fantasy in Italy. University of Minessota Press: Mineapolis.

Terán, 0. (1993). Nuestros años sesentas. La formación de una nueva izquierda intelectual argentina 1956-1966. Imago Mundi: Buenos Aires.

Viveros Vigoya, M. (1997). “Los estudios sobre lo masculino en América Latina. Una producción teórica emergente". Nomadas, n.6, marzo, Universidad Central, Colombia, pp. 1-12.

Woodley, D. (2010). Fascist and political theory. Critical perspectives on fascist ideology. Routledge: Londres.

Recibido: $14 / 02 / 2019$

Evaluado: 29/03/2019

Versión Final: 01/04/2019 